\title{
Twenty-five years' growth in a young red pine stand
}

\author{
by R.M. Newnham ${ }^{1}$
}

Growth data are presented by 5 -year intervals from age 20 to 45 years for a natural stand of red pine (Pinus resinosa Ait.) in eastern Ontario. At age 45 years, the top height (100 largest trees/ha) was $21.3 \mathrm{~m}$ and the volume $448 \mathrm{~m}^{3} / \mathrm{ha}$, with little evidence of any decline in either height or volume growth. Site index was approximately $24 \mathrm{~m}$ (at age 50 years) which is considerably superior to Plonski's site class 1 (Plonski 1974). Growth appears to be comparable to that of unmanaged plantations growing on the best sites on the Petawawa Research Forest. Height-diameter regressions are calculated for each plot measurement and compared with a combined regression for all plot measurements. The Weibull function was used to fit diameter distributions.
Des données de croissance sont présentées selon des intervalles de cinq ans répartis entre 20 et 45 ans pour un peuplement naturel de pin rouge (Pinus resinosa Ait.) de l'est de l'Ontario. A 45 ans, la hauteur maximale (100 plus gros arbres/ha) était de $21.3 \mathrm{~m}$ et le volume atteignait $448 \mathrm{~m}^{3} /$ ha, avec peu d'évidence de diminution de la croissance en hauteur ou en volume. L'indice du site était approximativement $24 \mathrm{~m}$ (à 50 ans) ce qui est considérablement supérieur à l'indice de site 1 de Plonski (Plonski 1974). La croissance semble être comparable à celle des plantations non aménagées croissant sur les meilleurs sites de la station de recherche de Petawawa. Les régressions hauteur-diamètre sont calculées à partir des mesures de chaque parcelle et comparées à une régression combinée de toutes les mesures. La fonction Weibull a été utilisée pour ajuster les distributions des diamètres.

\section{Introduction}

In the spring of 1965 , a 0.4 -acre $(0.162$-ha) permanent sample plot (PSP 449) was established in a natural stand of red pine (Pinus resinosa Ait.). The trees ranged in age from 14 to 25 years with a mean of 20 years. As red pine has infrequent good seed crops, the stand is probably more even-aged than the age range would indicate; part of the variation may be attributed to errors in estimating the age of individual trees. The site was on abandoned farmland (known locally as Arbour's Field) at the northeastern extremity of the Petawawa Military Reserve near Chalk River, Ontario. The stand was approximately 0.5 ha in extent and had been established with seed from scattered mature red pine trees, one of which remained at the southern boundary. It consisted of almost pure red pine with scattered trees of eastern white pine (P. strobus L. -3 trees on plot), white spruce (Picea glauca (Moench) Voss - 5 trees), white birch (Betula papyrifera Marsh. -2 trees), and poplar (Populus sp. 1 tree). Scattered undergrowth of willow (Salix spp.) was cut at the time of plot establishment. Stand density within the plot varied from fairly open to full crown closure. Competition among trees had obviously begun in the denser portions of the stand where some mortality in the smaller diameter classes had occurred.

The objective of this paper is to describe the development of the stand over a period of 25 years and, in particular, to show how the height/DBH relationship and the DBH distribution vary with age.

Although there are quite extensive plantations of red pine in eastern Ontario, the Arbour's Field stand is one of the few natural red pine stands in its age range. Because of the variation in stand density at the time of its first measurement, it provides a valuable database for studying competition and for developing single-tree distance-dependent growth models. It will also provide a basis for comparing the development of natural and planted stands of red pine.

\footnotetext{
${ }^{1}$ Research Scientist, Forestry Canada, Petawawa National Forestry Institute, Box 2000, Chalk River, Ontario K0J 1 J0.
}

\section{Methods \\ Data}

At the time of plot establishment, the position of each tree was mapped and the following measurements recorded: diameter at breast height $(4.5$ feet $(1.37 \mathrm{~m}))$ to the nearest 0.01 inch $(0.0254 \mathrm{~cm})$, and total height, height to the base of the live crown, crown width, and the length of the three internodes at breast height, all measured to the nearest 0.1 foot $(0.3048 \mathrm{~m})$. Age was determined for each tree by adding the number of rings on an increment core taken at breast height to the number of whorls below breast height. A more detailed description of plot establishment has been given by Newnham ${ }^{2}$.

Since 1965, the plot has been remeasured at five-year intervals, either in the spring $(1970,1975$, and 1990) before the onset of growth, or in the fall (1979 and 1984) after growth had ceased. The measurement of crown dimensions was discontinued after the 1975 remeasurement. The stand has not been subjected to any planned treatment but, from time to time, some unauthorized cutting of small trees has taken place (most noticeably in the 1979-84 period when eight trees, all less than $10 \mathrm{~cm} \mathrm{DBH,} \mathrm{were} \mathrm{removed).} \mathrm{The} \mathrm{removal}$ of these trees is unfortunate but is not thought to have had a noticeable effect on stand development. All measurements have continued to be made in imperial units in the standard format of the Petawawa National Forestry Institute for retention in the Institute's data bank. Computer programs have been developed to convert the basic data to metric (SI) units for subsequent analysis.

\section{Analysis}

The white pine and white spruce trees were included with the red pine while the broadleaved species (less than $1 \%$ of the basal area in 1964 and all dead by 1984) were excluded. By 1989 there was only one white pine and one (suppressed) white spruce left so that, for all practical purposes, the stand can be considered to be "pure" red pine.

\footnotetext{
${ }^{2}$ Newnham, R.M. (1966). Stand structure and diameter growth of individual trees in a young red pine stand. Can. Dep. For., Forest Manage. Inst. Intern. Rep. FMR-1.
} 


\begin{tabular}{|c|c|c|c|c|c|c|c|c|c|}
\hline $\begin{array}{c}\text { Age } \\
\text { (years) }\end{array}$ & $\begin{array}{l}\text { No. of } \\
\text { trees/ha }\end{array}$ & $\begin{array}{l}\mathrm{QMD}^{1} \\
\text { (cm) }\end{array}$ & $\begin{array}{c}\text { Mean } \\
\text { DBH }^{2} \\
(\mathrm{~cm})\end{array}$ & $\begin{array}{c}\text { Mean } \\
\text { height } \\
\text { (m) }\end{array}$ & $\begin{array}{l}\text { Mean top } \\
\text { height }^{3} \\
\text { (m) }\end{array}$ & $\begin{array}{c}\text { Basal } \\
\text { area } \\
\left(\mathrm{m}^{2} / \mathrm{ha}\right)\end{array}$ & $\begin{array}{c}\begin{array}{c}\text { Total } \\
\text { volume } \\
\left(\mathrm{m}^{3} / \mathrm{ha}\right)\end{array} \\
\end{array}$ & $\underset{\left(\mathrm{m}^{3} / \mathrm{ha}\right)}{\mathrm{MAI}^{4}}$ & $\begin{array}{c}\mathrm{PAI}^{5} \\
\left(\mathrm{~m}^{3} / \mathrm{ha}\right)\end{array}$ \\
\hline 20 & 1909 & 11.80 & 10.55 & 7.5 & 10.6 & 20.9 & 91.5 & 4.58 & \multirow{2}{*}{13.56} \\
\hline 25 & 1612 & 15.34 & 14.12 & 10.3 & 12.7 & 29.8 & 159.3 & 6.37 & \\
\hline 30 & 1415 & 18.09 & 17.02 & 13.0 & 14.6 & 36.4 & 228.3 & 7.61 & 13.80 \\
\hline 35 & 1303 & 20.17 & 19.18 & 15.8 & 17.0 & 41.6 & 302.7 & 8.65 & 14.88 \\
\hline 40 & 1180 & 22.32 & 21.58 & 18.3 & 19.1 & 46.2 & 373.6 & 9.34 & \multirow[t]{2}{*}{14.88} \\
\hline 45 & 1149 & 23.65 & 22.88 & 20.3 & 21.3 & 50.5 & 448.0 & 9.96 & \\
\hline
\end{tabular}

${ }_{1}^{1}$ Quadratic mean diameter at breast height.

${ }^{2}$ Arithmetic mean.

${ }^{3}$ Mean height of the 100 largest trees/ha.

${ }^{4}$ Mean annual increment.

${ }^{5}$ Periodic annual increment.

Total stem volumes were calculated using the formulae developed by Berry (1981) for metric form-class volume tables. The form class was assumed to be 70 , the standard value for red pine used on the Petawawa Research Forest. Top height was calculated as the mean height of the 16 largest DBH trees on the plot (equivalent to the largest 100 trees/ha). A number of regression models were tried to fit the relationship between height and DBH but a nonlinear, ChapmanRichards type function (Richards 1959) of the form

$$
(H-1.3)=b_{1}\left(1-e^{\mathrm{b}_{2} \mathrm{D}}\right)
$$

was selected as it yielded the overall most satisfactory results. Height/DBH regressions were calculated for each plot measurement and for all measurements combined. The Weibull function

$$
\left.F=1-\exp \{-[D-a) / b]^{\mathrm{c}}\right\}
$$

where $F$ is the cumulative distribution, $D$ is the DBH outside bark, and $a, b$, and $c$ are parameters, was fitted to the DBH distributions at each measurement using the secant, or DUD, method of the SAS NLIN procedure (SAS Institute Inc. 1988).

\section{Results and Discussion \\ Mean Stand Values}

Stand development over the 25 -year period was summarized (Table 1) and illustrated (Fig. 1). Stocking was reduced from 1909 to 1149 trees/ha while mean DBH (both quadratic and arithmetric) approximately doubled. Mean stand height increased at a steady $0.5 \mathrm{~m} /$ year with only slight evidence of a decline during the last 5-year period. If the average height of the 100 largest (DBH) trees is considered equivalent to the average height of dominants and codominants, and the current rate of growth is maintained for the next five years, this stand will have a site index of approximately $23.7 \mathrm{~m}$ - considerably superior to Plonski's site class 1 (Plonski 1974). Gross total volume at age 45 years was about $40 \%$ higher than that in Plonski's tables but nearly $20 \%$ lower than that given by Beckwith et al. (1983) for unthinned red pine plantations in Ontario. The growth of the stand, both in height and volume, appears to be closer to that of unmanaged red pine plantations growing on the best sites (site index $24 \mathrm{~m}$ at 50 years) at the Petawawa Research
Forest (Berry 1984). At age 45, the growth of the Arbour's Field stand was similar to the height and volume growth of the control plot of the Rockland plantation $(20.1 \mathrm{~m}$ and $472.5 \mathrm{~m}^{3} / \mathrm{ha}$ respectively; von Althen and Stiell 1990). Mean annual increment continues to increase and is currently at $9.96 \mathrm{~m}^{3} / \mathrm{ha}$. Periodic annual increment increased from $13.56 \mathrm{~m}^{3} / \mathrm{ha}$ during the first period to just under $15 \mathrm{~m}^{3} / \mathrm{ha}$ during the third, and appears to have stabilized at that level.

\section{Height/Diameter Relationships}

The relationship between total height $(\mathrm{H})$ and $\mathrm{DBH}$ for individual trees is shown (Fig. 2) for each measurement of the plot. At age 20 years, there was a spread in values of both DBH and height because, although the stand was relatively even-aged, there was a noticeable range in stand density.

The values of the b-coefficients in the Chapman-Richards function for each measurement are given (Table 2). Coefficient $b_{1}$ increases linearly with age while $b_{2}$ decreases, slowly at first but then with increasing rapidity. The data for all six measurements were then pooled and, based on these relationships, the following regression was calculated: $(H-1.3)=(1.95+0.414 A)\left[1-e^{\left(-0.0964-0.00001960 \mathrm{~A}^{2}\right) \mathrm{D}}\right]$ $N=1383 \quad R^{2}=0.9886$

where $A=$ stand age in years. The age-specific curves for this combined model can be seen to be very similar to the curves derived from data for the individual measurement ages (Fig. 2).

\section{Diameter Distributions}

Besides predicting rates of growth in DBH and height, and total volume production, it is also important to have some estimate of the distribution of tree sizes at each stage of a stand's development. This information provides insight into the types and quantities of end product - pulpwood, sawlogs, poles, etc. - that may be obtained from the stand and may improve the estimates of harvesting production rates and costs.

In recent years, there have been several successful attempts to fit the Weibull function to diameter distributions (Bailey and Dell 1973, Clutter and Allison 1974, Rennolls et al. 

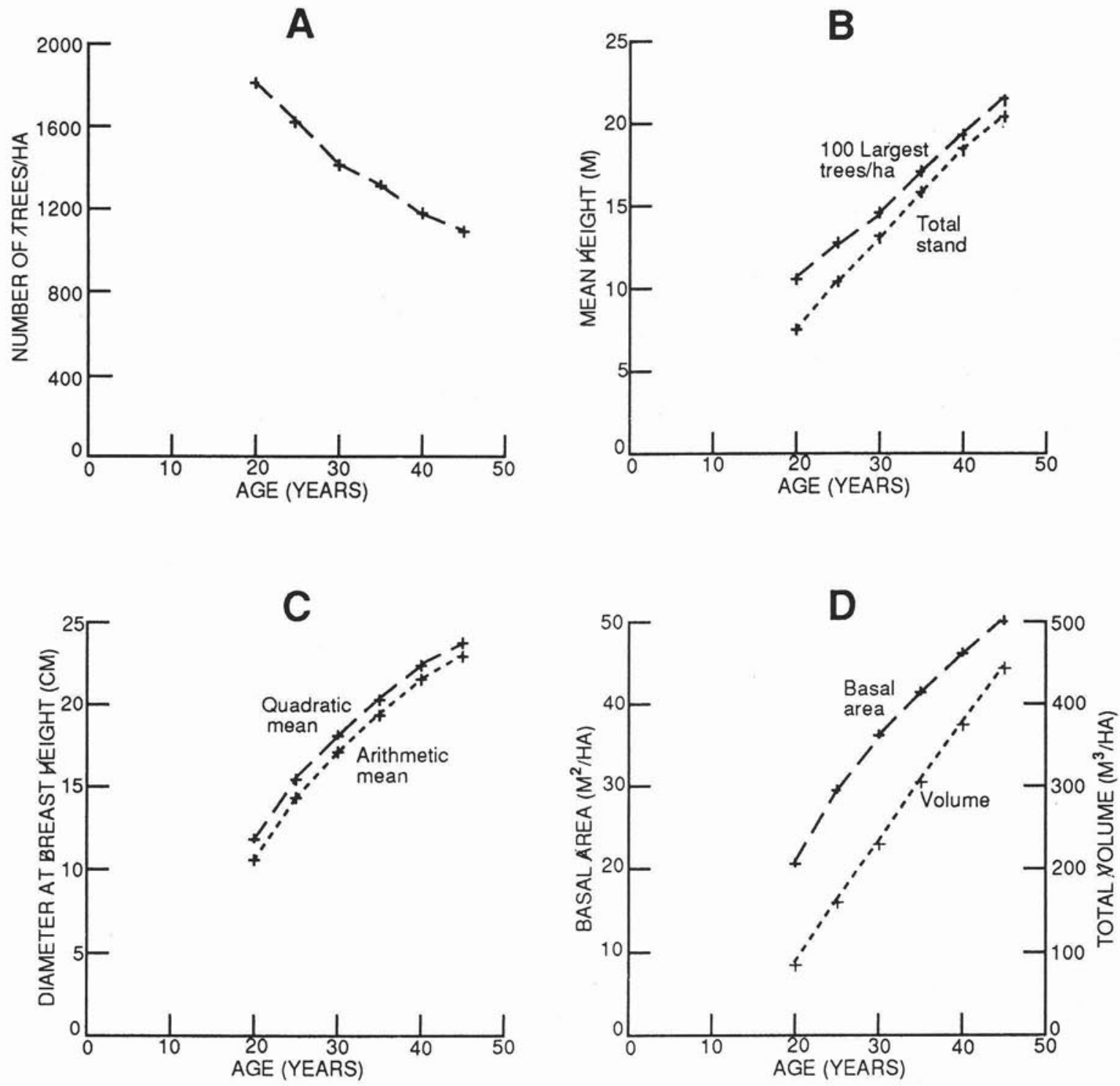

E

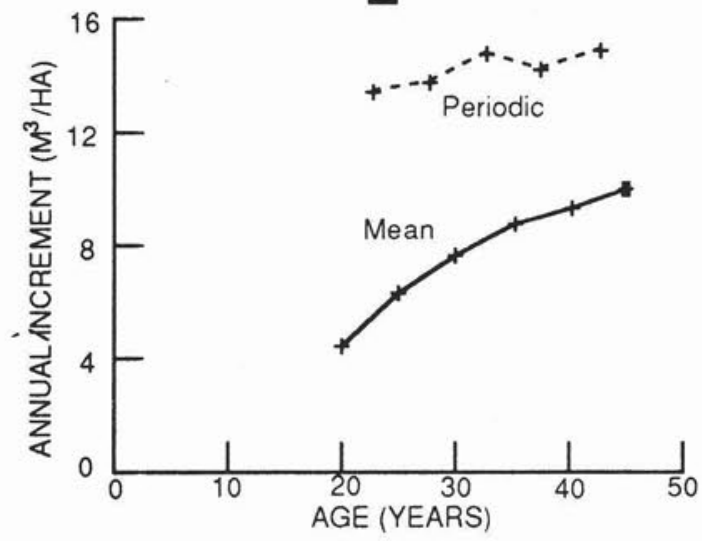

Figure 1. Growth and development of PSP 449. (A) Stocking (B) Height (C) Diameter at breast height (D) Basal area and volume and (E) Mean and periodic annual increment. 

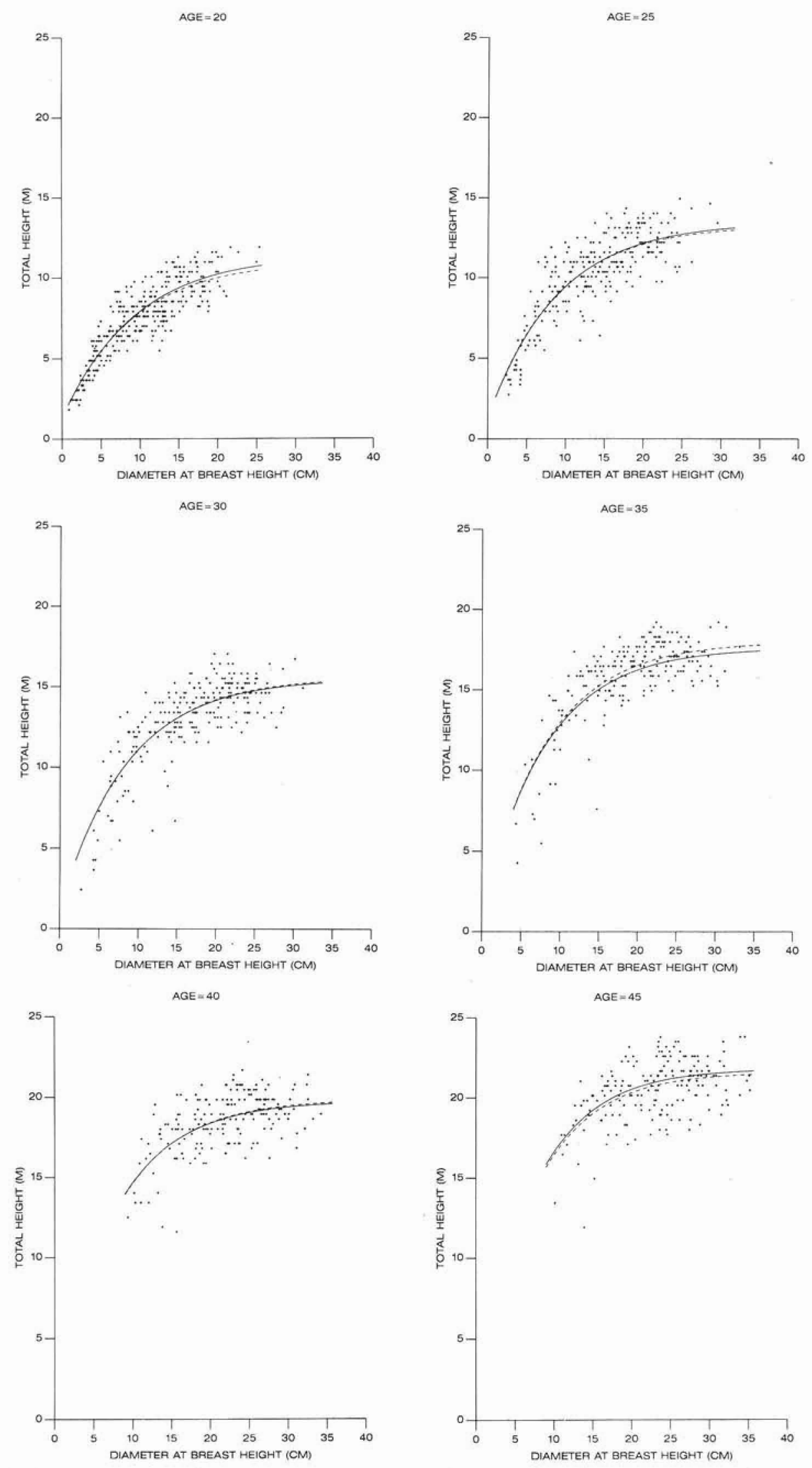

Figure 2. The relationship between height and $\mathrm{DBH}$ at each measurement. The broken ${ }_{2}$ lines are for the regression: $H=1.3+b_{1}$ $\left(1-e^{\mathrm{b}_{2} \mathrm{D}}\right)$; the solid lines are for the regression: $H=1.3+\left(c_{0}+c_{1} A\right)\left[1-e^{\left(c_{2}+c_{3} A^{2}\right) D}\right]$. 
Table 2. Parameter values for the height/diameter regressions and for the Weibull diameter distributions

\begin{tabular}{|c|c|c|c|c|c|c|c|c|c|}
\hline \multirow{3}{*}{$\begin{array}{c}\text { Age } \\
\text { (years) }\end{array}$} & \multirow{3}{*}{$\begin{array}{c}\text { No. of } \\
\text { observations }\end{array}$} & \multirow{2}{*}{\multicolumn{3}{|c|}{$\begin{array}{l}\text { Height/diameter regression: } \\
H=1.3+b_{1}\left(1-e^{b_{2} \mathrm{D}}\right)\end{array}$}} & \multicolumn{5}{|c|}{$\begin{array}{c}\text { Weibull function: } \\
F=1-\exp \left\{-(D / b)^{\mathrm{c}}\right\}\end{array}$} \\
\hline & & & & & & & & & Critical \\
\hline & & $b_{1}$ & $b_{2}$ & $R^{2^{1}}$ & $b$ & $c$ & $R^{2^{2}}$ & statistic $^{3}$ & $(P=0.10)$ \\
\hline 20 & 309 & 9.83 & -0.1100 & 0.9748 & 12.21 & 1.941 & 0.9945 & 0.037 & 0.069 \\
\hline 25 & 261 & 12.12 & -0.1123 & 0.9783 & 16.27 & 2.43 & 0.9951 & 0.029 & 0.076 \\
\hline 30 & 229 & 14.47 & -0.1124 & 0.9853 & 19.41 & 2.978 & 0.9942 & 0.035 & 0.081 \\
\hline 35 & 210 & 16.84 & -0.1177 & 0.9900 & 21.67 & 3.417 & 0.9967 & 0.040 & 0.084 \\
\hline 40 & 190 & 18.61 & -0.1257 & 0.9917 & 23.83 & 4.111 & 0.9972 & 0.041 & 0.089 \\
\hline 45 & 184 & 20.36 & -0.1356 & 0.9934 & 25.33 & 4.295 & 0.9966 & 0.041 & 0.090 \\
\hline
\end{tabular}

${ }^{1}$ For nonlinear regressions, $R^{2}$ values should be viewed with caution as they may give false indications of the goodness of fit of the model.

${ }^{2}$ These values of $R^{2}$ indicate the degree of agreement between the predicted and observed cumulative frequencies.

${ }^{3}$ For the K-S statistic, D, to be significant at $P=0.10$, its value must be greater than the corresponding critical $\mathrm{D}$-value.

1985, Magnussen 1986). This function is very flexible and can fit distributions that range from very skewed, reverse-J shaped, to the more conventional bell-shaped including both "flattened" and "peaked" forms.

Weibull functions were fitted to the DBH distributions for each of the six measurement years for PSP 449. Initial analyses showed that, in each case, the value of the location parameter, a, was negative. This would result in predicted frequencies in negative DBH classes. Because these could not occur in practice, the frequencies for such classes would be included in the lowest positive class, creating a noticeable bias. The analyses were therefore repeated with the value of the a-parameter fixed at zero. The values of the b-and c- parameters are given (Table 2). The Kolmogorov-Smirnov one-sample test (Siegel 1956) was used to test for goodness of fit. The K-S statistic, D, is the largest divergence between the observed and predicted cumulative distributions. The critical D-values indicate the magnitude that these divergences would have to attain for a significant difference. Not one of the predicted Weibull distributions was significantly different from the observed distributions at $P=0.10$.

Figure 3 shows both the observed and the predicted diameter distributions. Although the shape of the distribution changes from being positively skewed at age 20 years to typically bell-shaped at ages 30 and 35 years and, finally, slightly negatively skewed at age 45 years, the fit of the Weibull function is very good in all cases.

Figure 3 also shows the diameter distribution of dead trees. Mortality appears to have been mainly due to competition as it was confined to the smaller DBH classes in each case. The predicted mortality in a $2-\mathrm{cm}$ diameter class over a 5-year period, p, was calculated from the formula:

$$
M_{\mathrm{p}}=N_{\mathrm{p}}-\left(N_{\mathrm{p}+1}+n^{+1}+n^{+2}\right)
$$

where $M_{\mathrm{p}}$ is the number of trees that died during period $p$, $N_{\mathrm{p}}$ and $N_{\mathrm{p}+1}$ are the numbers of trees in the class at the beginning and end of period $p$ (predicted from the Weibull function), and $n^{+1}$ and $n^{+2}$ are, respectively, the predicted numbers of trees that moved up one and two diameter classes during the period (movements upward greater than two classes were not predicted). Because the number of trees dying in a 5-year period is relatively small, satisfactory fits of predicted to observed distributions are often difficult to obtain. However, Figure 3 shows that the method used in this study does give reasonable results and is worthy of further testing.

Another approach to predicting upward movement between diameter classes with time is by using probability matrices (Usher 1966, Bonnor and Magnussen 1988). Basically, this method consists of multiplying a vector representing the frequency distribution of $\mathrm{DBH}$ at the beginning of a period by a matrix of probabilities, the result being a vector representing the frequency distribution at the end of the period. The elements of this matrix are, for each class, the probabilities of a tree dying, remaining in the class, or moving up one, two, or more classes during the period. For selection and uneven-aged forests, a vector representing the probability of a previously unenumerated tree being recruited to a diameter class (ingrowth) must also be included. Because the number of trees on which each element is based is generally small, the probabilities estimated from empirical data are often uneven. Bonnor and Magnussen (1988) used regression analysis to "smooth" the probabilities.

This study has shown that the diameter distribution at the end of each five-year period can be described accurately by the Weibull function. Using the predicted distribution by $2-\mathrm{cm}$ classes and assuming that the ranking by DBH does not change over time, it is possible to predict the average movement between classes in each period. The resulting probability elements will be "smoothed".

\section{Conclusions}

The growth of the Arbour's Field natural red pine stand appears to be comparable with eastern Ontario plantations of similar site index. At age 45 years, there is little indication of any decline in growth in either height or total volume.

For this particular plot, it appears that a single regression, based on the Chapman-Richards growth function, can be used for estimating height from $\mathrm{DBH}$ and age. The data also confirmed the applicability of the Weibull function for fitting diameter distributions. The method suggested here for "smoothing" probability matrices warrants further investigation.

\section{Acknowledgements}

E.E. Rideout and the late M.J. MacNamara assisted in plot establishment and early remeasurements. D.J. McGuire and C.F. Robinson assisted in the remeasurements after 1975 . 

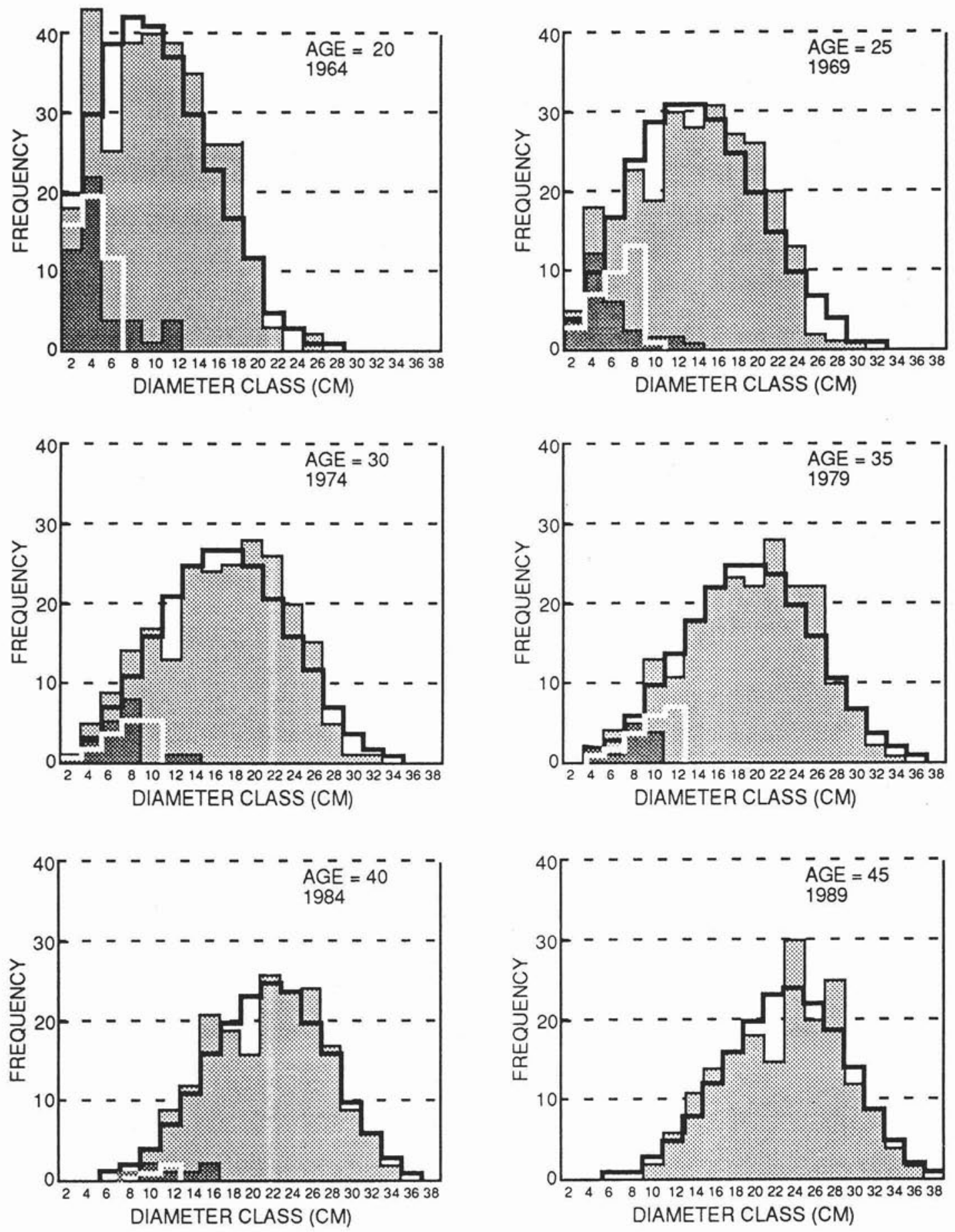

Frequency (no. of trees):

Observed Distribution

$\square$ Weibull Distribution

Mortality in next five years:

Observed

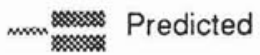

Figure 3. The observed and predicted (by the Weibull function) diameter and mortality distributions. Two-cm diameter classes are identified by their mid-points. 


\section{References}

Bailey, R.L. and T.R. Dell. 1973. Quantifying diameter distributions with the Weibull function. For. Sci. 19: 97-104. Beckwith, A.F., P. Roebbelen and V.G. Smith. 1983. Red pine plantation growth and yield tables. Ont. Min. Nat. Res., Toronto, Ont., For. Res. Rep. 108.

Berry, A.B. 1981. Metric form-class volume tables. Dep. Environ., Can. For. Serv., Chalk River, Ont., Inf. Rep. PI-X-10.

Berry, A.B. 1984. Volume and biomass yield tables for unthinned red pine plantations at the Petawawa National Forestry Institute. Dep. Environ., Can. For. Serv., Chalk River, Ont., Inf. Rep. PI-X-32.

Bonnor, G.M. and S. Magnussen. 1988. Predicting stem diameter distributions from growth probability equations. In A.R. Ek et al. (Ed.) Forest growth modelling and prediction, Volume 1, USDA Forest Serv., N. Cent. Forest Exp. Sta./Soc. Am. For. Publ. SAF-87. 12: 192-200.

Clutter, J.L. and B.J. Allison. 1974. A growth and yield model for Pinus radiata in New Zealand. In J. Fries (Ed.) Growth and yield models for tree and stand simulation. Royal Coll. For., Stockholm, Res. Notes: 136-160.
Magnussen, S. 1986. Diameter distributions in Picea abies described by the Weibull model. Scand. J. For. Res. 1: 493-502.

Plonski, W.L. 1974. Normal yield tables (metric) for major forest species of Ontario. Ont. Min. Nat. Res.

Rennolls, K., D.N. Geary and T.J.D. Rollinson. 1985. Characterizing diameter distributions by the use of the Weibull distribution. Forestry 58: 57-66.

Richards, F.J. 1959. A flexible growth function for empirical use. J. Exp. Bot. 10(29): 290-300.

Siegel, S. 1956. Nonparametric statistics for the behavioural sciences. McGraw-Hill Book Co., Inc., New York.

Statistical Analysis System Institute, Inc. 1988. $\mathrm{SAS} / \mathrm{STAT}^{\mathrm{TM}}$ User's guide, Release 6.03 edition. SAS Inst. Inc., Cary, NC.

Usher, M.B. 1966. A matrix approach to the management of renewable resources, with special reference to selection forests. J. Appl. Ecol. 3: 355-367.

von Althen, F.W. and W.M. Stiell. 1990. A red pine case history: development of the Rockland plantation from 1914 to 1986. For. Chron. 66: 606-610.

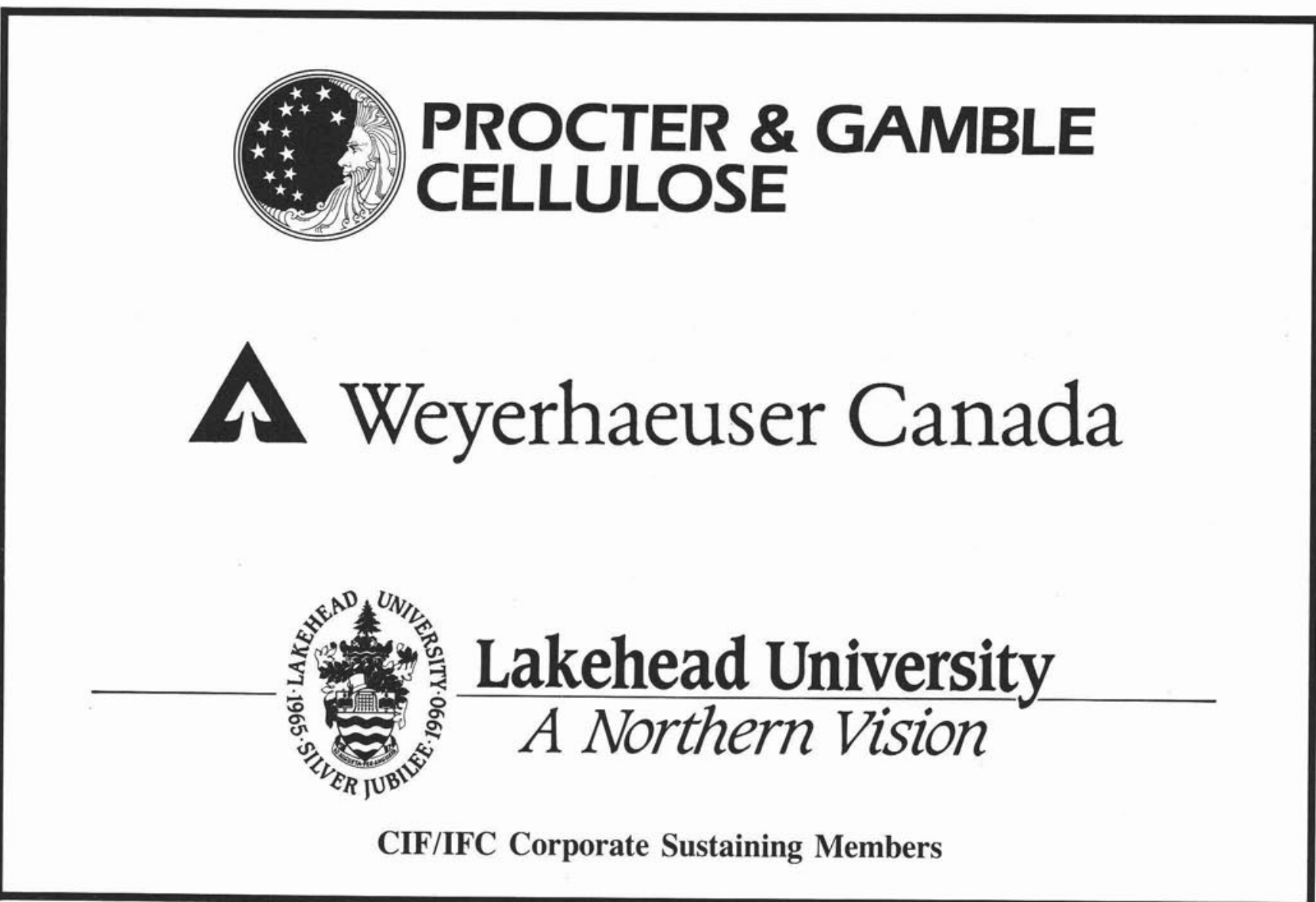

